\title{
Health needs of immigrants: rights to treatment and confidentiality
}

\author{
Louise Melvin
}

\section{Introduction}

Immigration has featured much in the media and political arena of late. Foreign patients can present particular challenges to health professionals due to language barriers, cultural differences, transient residency and sometimes complex medical and social problems. Uncertainty about immigration status and rights to National Health Service (NHS) treatment can further complicate patient care. In this issue we feature a scenario adapted from a real case. (The patient consented to disclosure. Her name has been changed.)

\section{Clinical scenario}

Precious is a 25-year-old woman from Rwanda. Her family were murdered and butchered in front of her during the genocide in 1994. While applying for asylum in the UK, she has been attending your practice for support and contraception. She has now lost her claim for asylum as she cannot show that her life would be threatened if she were returned to Rwanda. She has just received a tip-off that immigration authorities are about to deport her, so she has left her National Asylum Support Service (NASS) accommodation and gone to live with her partner in an attempt to evade deportation. He is controlling and aggressive. On finding her packet of progestogen-only pills (POPs) he threw them away, telling her that he wants to have a child. She has asked you not to let anyone, including your colleagues in the practice, know where she is living. If you were her general practitioner (GP) or nurse what would you do?

\section{The panel}

Four professionals (detailed in Box 1) were invited to discuss what they would have done.

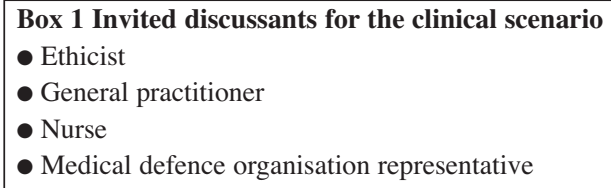

\section{Ethicist}

The Department of Health states that GP practices should not register failed asylum seekers. However, GPs do have the discretion to accept failed asylum seekers as registered NHS patients, and if it is the clinical opinion of a health care professional that emergency (or 'immediately necessary') treatment is required, this should be provided free of charge. In which case, there should be no issue with Precious' entitlement to treatment here, as the doctor could argue that providing contraception is immediately necessary treatment.

J Fam Plann Reprod Health Care 2005; 31(4): 331-332

Simpson Centre for Reproductive Health, Royal Infirmary of Edinburgh, Edinburgh, UK

Louise Melvin, MRCOG, DFFP, Specialist Registrar

Correspondence to: Dr Louise Melvin, Simpson Centre for Reproductive Health, Royal Infirmary of Edinburgh, 51 Little France Crescent, Edinburgh EH16 4SA, UK.

E-mail: Louise.Melvin@ed.ac.uk
The issue of 'best interests' isn't really relevant to the decision as to whether Precious should be treated or not. A competent patient decides what is in her own best interests, not the doctor. Of course, this does not hold if the patient is non-competent, in which case the doctor is required to act in what he/she considers to be the best interests of his patient. There is nothing in the above scenario to suggest Precious is anything other than competent.

Her request for POPs seems perfectly reasonable. Furthermore, given Precious' domestic situation, I'd suggest that the duty of care the doctor has established with his patient by agreeing to see her extends to exploring the possibility of a contraceptive method her partner could less easily interfere with. And, given that her partner is 'controlling and aggressive' and attempting to coerce Precious into having a child, it would be pertinent to investigate her physical safety. (Perhaps an exploration of the psychological and emotional impact of her partner's behaviour would be considered beyond the scope of immediately necessary treatment.)

Precious has asked the doctor to withhold information about her address. This is a perfectly understandable request given her fear of deportation. Would the doctor be acting contrary to General Medical Council (GMC) guidelines if he/she agreed? It seems not. The GMC tells us that most patients understand and accept that information must be shared within health care teams in order to provide care. However, if a patient objects to particular information being shared with others in the team, doctors must respect this, except where it would put others at risk of death or serious harm, for example, in child protection cases.

Since Precious has no children, the doctor could uphold her request and offer appropriate treatment without any concern about transgressing legal or professional guidelines.

\section{General practitioner}

Precious is in a very vulnerable situation both legally, having lost her claim for asylum, and socially, since she is dependent on a partner who is described as controlling and aggressive. She is likely to be feeling very insecure and mistrusts health workers, fearing that she will be reported to immigration officials. The first thing I would do would be to explain that myself and all my colleagues (including interpreters) are bound by confidentiality and that we will not reveal her whereabouts without her permission. However, I would also explain that it is important for other health workers to know where she is living, in order to plan care effectively and in case she needs an emergency visit. She may now be living outside the practice area, but it would not be a good time to be moving practices and I can see her now for immediately necessary care.

I would ask her about her relationship with her partner and check whether she is at risk of violence now and whether he has ever been violent in the past. Does she want to stay with him and does she want a child? She may feel that she has nowhere else to go, particularly given her vulnerable legal situation. She may be a survivor of rape in Rwanda or subsequently, and may have conflicting feelings concerning sex, relationships and pregnancy. If she has been at risk, has she been offered screening for sexually transmitted infections, including HIV? 


\section{CLINICAL CONUNDRUM}

If she decides to leave her partner, she will need help with housing - all the more challenging given her precarious legal situation - and I would involve a welfare advice agency. If she decides to stay with her partner, I would ensure that she has information on what to do if she is in a situation where she feels unsafe, and phone numbers of organisations that support women at risk of violence. I would also ask if she would like to be in contact with people from her own community, whilst being aware that communities in exile may be divided (Rwanda being one such example) and people may not wish to be in contact.

She urgently needs good legal advice and I would ensure that she has access to an immigration lawyer (contact the Immigration Law Practitioners Association for advice on a reputable lawyer ${ }^{1}$ ). She may have grounds for appeal on her asylum claim.

Currently failed asylum seekers and other undocumented migrants are liable for NHS hospital charges, unless they have an emergency problem or are already receiving care for a specific illness. They are still eligible for free primary care, although the Government is due to publish a decision, which may result in the withdrawal of all free health care (except emergencies or treatment for certain infectious diseases) from people who have been refused asylum in the UK.

Many people who have failed in their asylum claim and are facing deportation are living under extremely stressful circumstances, which threaten their mental well-being. There have been several reports of suicide and attempted suicide at this time and many health workers are greatly concerned that people will be unable to access services that they need. ${ }^{2}$

Before Precious leaves the surgery I would ensure that I have a reliable way of contacting her, and that she has booked a follow-up appointment. I am unlikely to have completed everything within the allotted time, particularly if we are working with an interpreter, and I will want to see her again to check on how she is doing.

\section{Nurse}

In my experience of working with asylum seekers, sadly this is all too common a situation. Precious' case displays several vulnerability factors. It is therefore important to offer ongoing care and support. The Department of Health guidance is not mandatory and, in certain parts of the UK, health authorities have taken the decision to provide continuing care of failed asylum seekers. At the very least, GPs may provide immediately necessary care.

My first step would be to try to gain the trust of Precious. I would be loathe to breach confidentiality and would assure her that I would not disclose information to anyone without her permission. It is not the responsibility of health professionals to police immigration, and it can be difficult to control the circulation of patient information, even among the professional community. If Precious were HIV positive, I would still maintain confidentiality unless I felt others were unknowingly at risk.

I would then attempt to get the whole story, especially details of the relationship with her partner. She may have received inaccurate advice and be under pressure from others. Having explored the situation and established the facts, we would systematically go through her options. She is entitled to remain in the UK until issued with a letter of deportation, and it may be safer for her to stay in the NASS accommodation. The NASS ${ }^{3}$ should be in a position to help those at risk of violence. She may even be able to claim asylum on those grounds if her partner had accompanied her into the country. I would suggest that she seeks the advice of a lawyer with regard to making an appeal.

\section{Medical defence organisation representative}

There is nothing in this scenario that requires obligatory disclosure. There are of course complex ethical and clinical decisions to consider.

The patient primarily attended for support and contraception. If her POPs have been thrown away then alternative methods of contraception need to be discussed with the patient, for example, one of the depot methods. One would also have to consider the issue of pregnancy.

If the patient requires medical care it is important to maintain a relationship of trust. One must weigh up the risks and benefits of respecting the patient's wishes in relation to non-disclosure of her current address. Such an agreement might be sensible in order to secure contact with the patient. The patient can be reassured that the practice would regard any information as confidential but it may take some time before she is willing to consent to a wider disclosure. This really is a matter for an individual doctor to decide whether a breach of confidentiality can be justified. If information is disclosed to colleagues the patient must be informed; however, this may fragment the relationship. Such decisions require careful consideration of the consequences.

It is important to ascertain from the patient what she wants to do in terms of accommodation, particularly if there are questions about her safety if she remains with her current partner. Whilst it is not strictly a medical matter, the patient must have access to proper legal advice.

Overall, it is sensible to maintain contact with the patient until her immediate medical needs have been attended to. There is no obligation to disclose information about the patient's whereabouts. There are serious issues about preserving the patient's trust. One must ensure that she is provided with appropriate health care within a framework consistent with current professional and ethical guidance. These are difficult decisions, which ultimately one may have to justify.

\section{Discussion}

The discussants agree that a breach of confidentiality cannot be justified and that immediately necessary care can be provided, including suitable contraception. Women in such a vulnerable position should ideally be offered ongoing health care, legal advice and support from the various agencies mentioned in this article.

\section{Acknowledgements}

The author would like to thank Dr Paul Williams for providing the case scenario and the panel members for their input. A listing of the individual panel members who have contributed to the Clinical Conundrum section of the Journal appears on page 342 of this issue.

References

1 Immigration Law Practitioners Association (ILPA). http://www.ilpa. org.uk.

Medact. http://www.medact.org.

3 National Asylum Support Service. http://www.ind.homeoffice.gov. uk/ind/en/home/applying/national_asylum_support.html [Accessed 20 July 2005].

Bibliography

1 British Medical Association. Asylum Seekers: Meeting Their Healthcare Needs. London, UK: BMA, 2002.

2 Burnett A, Fassil Y. Meeting the Health Needs of Refugees and Asylum Seekers in the UK, an Information and Resource Pack for Health Workers. London, UK: London Directorate of Health and Social Care and Department of Health, 2002. http://www.london. nhs.uk/newsmedia/publications/Asylum_Refugee.pdf [Accessed 20 July 2005].

\begin{tabular}{l}
\hline USEFUL CONTACT DETAILS \\
Health for Asylum Seekers and Refugees Portal \\
http://www.harpweb.org.uk \\
Refugee Council \\
http://www.refugeecouncil.org.uk, www.scottishrefugeecouncil.org.uk \\
Medical Foundation for Victims of Torture \\
http://www.torturecare.org.uk
\end{tabular}

